\title{
Pore Hierarchies in High-Temperature Composite Refractories
}

\author{
W. E. Lee, S. Zhang and S. Hashimoto
}

University of Sheffield, Dept. of Engineering Materials, Mappin St., Sheffield, S1 3JD, UK

Refractories are high-temperature, porous, composite materials containing from 5-90 volume \% porosity. They are enabling materials used to line furnaces for production of other materials including metals, ceramics, glasses, cements, semiconductors and single crystals [1]. Massive volumes of them are used successfully in some of the most severe environments seen by materials but researchers often neglect them as being too "traditional" and low tech. This is far from the case and their microstructural design is often complex and beautiful. Pores are present because the firing step in their fabrication, unlike in other ceramics, induces little if any shrinkage and densification; it is simply a bonding operation to improve properties [2]. Pores occur within and between the solid materials in the microstructure after the shape forming operation. While they are not removed on firing their size, shape and distribution may be altered by a range of processes including thermal expansion/contraction of phases present, phase transformations involving volume change, local solid state and liquid phase sintering, vitrification and reactions between phases and/or the atmosphere.

The porosity in refractories ranges from macroscopic (mm scale) to microscopic ( $\mu \mathrm{m}$ to $\mathrm{nm}$ scale), may be open or closed and may be located in the grain/aggregate phases or the bond/matrix system or both. While refractories may be made as pre-fired bricks or shapes they are more often made as monolithics or unshaped mixtures, which can be installed and shaped in situ. Such monolithics include castables which are dry powder mixes which when water is added can be shaped by casting or vibrating, a hydraulic cement chemical bond forms at room temperature and converts to a physical ceramic bond on firing. The pore distribution is a strong function of installation technique. Typically, thermo-mechanical and chemical properties of refractories are also a function of the total pore system so its quantitative characterisation is important. Pores occur over a range of length scales (hierarchies) in the refractories microstructure and it is useful to perform interrupted firing experiments to catch the evolution of the pore structure on firing.

The microstructural evolution on firing and quenching a commercial vibratable ultralow cement castable has been fully characterized and related to high-temperature properties [3]. Figure 1 shows that after firing at $1200^{\circ} \mathrm{C}$ low melting calcium aluminium silicate (CAS) liquid formed in the matrix leaving bright CAS-rich regions around the cement agglomerates, while dispersed microsilica in the bond started to react with alumina from hydratable alumina agglomerates forming an aluminosilicate (AS) rim around them. Pores are black in this image and occur predominantly in the matrix system. They are seen e.g. as:

- rims around the calcium dialuminate $\left(\mathrm{CA}_{2}\right)$ agglomerates arising from its formation in the cement via reaction of calcium aluminate with alumina and shrinkage contraction,

- fine $(\mu \mathrm{m})$ intragranular pores in the matrix from incomplete sintering.

- $\mathrm{nm}$ scale layer pores within the hydratable alumina agglomerates (labelled AS).

The origins of the layer pores can be traced back to the production of the hydratable alumina from Gibbsite $\left(\mathrm{Al}(\mathrm{OH})_{3}\right)$ using the Bayer process. The calcined product of the Bayer process is made up of transition alumina which is pseudomorphic with the original Gibbsite (Figure 2). The volume change associated with the calcination of Gibbsite to alumina and the orientation relation between 
the Gibbsite and alumina lead to this pore morphology. The emergence of refractory phases such as calcium hexaluminate, magnesium aluminate spinel and mullite in commercial castable refractories has been observed to have beneficial effects on hot bend strength and refractoriness under load due to development of morphologies which interlocked other phases and to pore filling from expansile reactions.

\section{References}

[1] WE Lee, Chapter 4.12 pp.363-385 "Refractories" in Comprehensive Composite Materials (edited by A Kelly and C Zweben) Volume 4. Ceramic, Carbon and Cement Matrix Composites (Elsevier 2000).

[2] WE Lee and WM Rainforth, Ceramic Microstructures: Property Control by Processing. (Chapman and Hall 1994).

[3] H Sarpoolaky, KG Ahari and WE Lee, "Influence of in-situ Phase Formation on Microstructural Evolution and Properties of Castable Refractories," Ceramics International 2002.

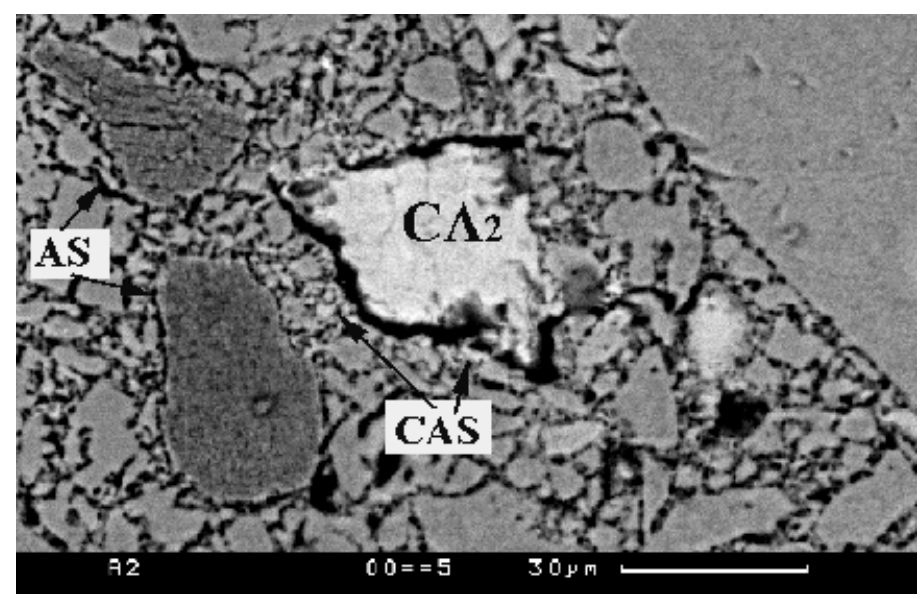

FIG 1. Backscattered electron SEM image of an ultralow cement castable after $3 \mathrm{~h}$ at $1200^{\circ} \mathrm{C}$.

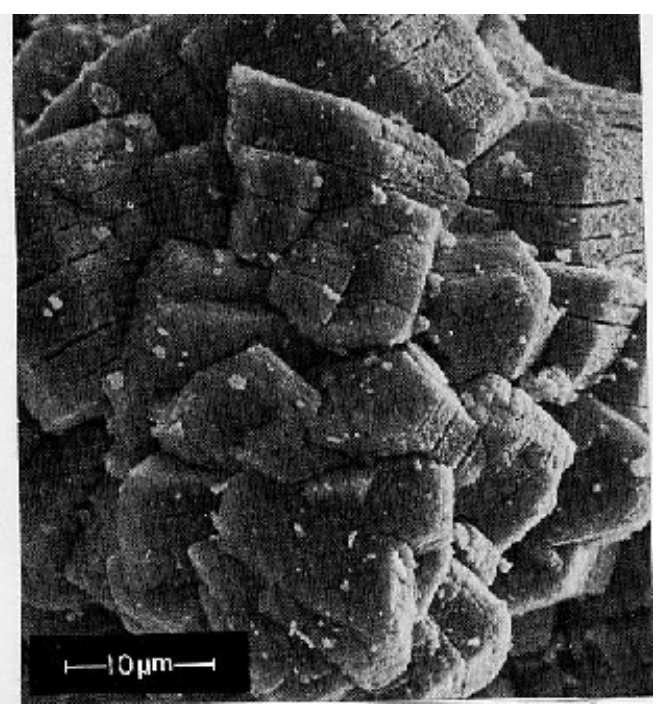

FIG 2. Secondary electron SEM image of pore fissures in alumina formed by dehydroxylation of Gibbsite at $1150^{\circ} \mathrm{C}$. 